\title{
Competências de Gestão para a função de Enfermeiro Gestor
}

\author{
Maria Cristina Bompastor Augusto 1 \\ augusto.cristina@gmail.com 1 \\ NID_RH - Politécnico do Porto \\ Ana Cláudia Rodrigues 2 \\ anarodrigues@eu.ipp.pt 2 \\ NID_RH - Politécnico do Porto
}

\begin{abstract}
Resumo
O conceito de competências tem sido amplamente empregado nas práticas de Gestão de Recursos Humanos. Quando outras áreas, como a Enfermagem, concilia a prestação de cuidados com a própria gestão do seu capital humano, torna-se preponderante efetuar um cruzamento dos dois mundos. Este artigo pretende identificar as competências de gestão para a função de Enfermeiro Gestor, ou seja, para aqueles que exercem funções de gestão nas organizações, com base numa revisão de literatura. Foi possível identificar 189 competências, que se agruparam nas categorias: Gestão de recursos humanos, Competências interpessoais, Organização e planeamento, Competências técnicas de enfermagem, Comunicação, Preocupação pela qualidade, Conhecimento de políticas de saúde, Resiliência e motivação, Liderança, Competências técnicas de gestão, Resolução de problemas, Iniciativa, Pensamento crítico, Tecnologias de informação e Comunicação, Ética, Adaptação à mudança, Trabalho em equipa e Autonomia. Posteriormente, efetuou-se uma comparação das competências identificadas, com um estudo de referência publicado em 2010 pelo International Council of Nurses (ICN).
\end{abstract}

Palavras chave: Competências; Competências de Gestão; Enfermeiros com funções de gestão

\section{Introdução}

São inúmeras as modificações que a área da saúde tem sofrido nos últimos tempos, numa tentativa de se adaptar às crescentes exigências transversais marcadas pela globalização e competitividade. O setor público não é exceção, sendo fundamental que a sua administração se adapte às novas contingências. Para isso, será fulcral que se invista nas pessoas, que se mude o sistema de valores e, também, que se modifiquem os modelos de liderança predominantes nas organizações públicas (Carapeto \& Fonseca, 2006). Os enfermeiros com funções de chefia, como profissionais de saúde integrantes do Serviço Nacional de Saúde (SNS), deverão estar preparados para lidar com as constantes mutações tecnológicas, organizacionais e humanas (e.g. Ruthes \& Cunha, 2009), e para desenvolver as competências necessárias para o melhor desempenho da sua função.

A carreira de enfermagem em Portugal está legislada em duas categorias: a de Enfermeiro e a de Enfermeiro Principal (Decreto-lei 247/2009 e Decreto-lei 248/2009, de 22 de Setembro). 
Enquadradas na categoria de Enfermeiro Principal estão previstas funções de gestão no SNS. A Ordem dos Enfermeiros (OE) apresentou um documento em Outubro de 2003, onde estão definidas as "Competências dos Enfermeiros de Cuidados Gerais". A segunda categoria, a de Enfermeiro Principal, apesar de estar regulada pela legislação que mencionamos, ainda não se encontra aplicada. Uma das limitações prende-se com o congelamento das carreiras da função pública. Dissecando o descritivo da função de Enfermeiro Principal, verificamos que este, para além das funções inerentes à categoria de Enfermeiro, assume outras relacionadas com a gestão do processo de prestação de cuidados de saúde. Também está previsto que os enfermeiros titulares dos órgãos de estrutura intermédia das organizações do SNS (Decreto-lei 247/2009 de 22 de Setembro) ou, com cargos de chefia nomeados em comissão de serviço, para as estruturas intermédias das organizações do SNS (Decreto-lei 248/2009 de 22 de Setembro) terão que ser privilegiadamente Enfermeiros Principais. Enquadrado na necessidade de adaptação às mudanças conjunturais e na necessidade de operacionalizar algumas das funções de Enfermeiro Principal, o objetivo deste trabalho será identificar as competências de gestão para os enfermeiros com funções de chefia, a partir de uma análise da literatura.

\section{Enquadramento Teórico (Desenvolvimento)}

Ainda que o conceito de competências exista desde a Idade Média, "na qual era considerada como a capacidade de apreciar e julgar certas questões ou realizar determinados atos" (Ruthes \& Cunha, 2007, p.110), foi nas últimas décadas que este começou a ser mais utilizado. A competência surge em 1960, nos Estado Unidos e no Canadá, e é com o trabalho de McClelland (1973) num artigo intitulado Testing for competency rather than intelligence, onde o conceito de competência aparece articulado com o de formação e mercado de trabalho. Apesar de este autor continuar a ser uma referência na literatura associada às competências, a definição do conceito não encerra consenso. De acordo com Silva (2008), o conceito de competências pode organizarse em duas grandes linhas: competência como padrão de desempenho, que permite reconhecer o trabalho como competente (competence); competência como comportamento exibido pelo indivíduo que permite a execução do trabalho com competência (competency). A primeira linha, baseada no padrão de desempenho, considera a competência como a capacidade para 
desempenhar atividades dentro de uma função, e é muito utilizada no Reino Unido, nomeadamente no setor público. A segunda é mais utilizada no contexto norte-americano, e focaliza-se nos comportamentos que o individuo necessita de demonstrar (Hoffman, 1999, cit. por Silva, 2008), ou seja, na habilidade e qualidade que o indivíduo apresenta em ordem a exibir um desempenho competente (Woodrufe, 1991, cit. por Silva, 2008). Para além destas duas abordagens mais consensuais, Silva (2008) apresenta uma terceira, que considera que na origem dos comportamentos que têm relação com desempenhos superiores estão atributos e características basilares dos indivíduos - competencies.

Outro autor que propõe uma nova forma de compreender as competências é Ceitil (2007). Este apresenta quatro perspetivas principais para perceber o conceito de competências: as competências como atribuições; as competências como qualificações; as competências como traços ou características pessoais; e as competências como comportamentos ou ações. $\mathrm{Na}$ primeira, as competências são consideradas como um elemento externo à pessoa, pois são inerentes ao exercício de determinados cargos, funções ou responsabilidades. Nesta perspetiva as competências existem como um elemento formal, quer sejam usadas ou não por um indivíduo. A segunda perspetiva, competências como qualificações, apoia-se na noção de competências como um conjunto formal de saberes e de técnicas que podem ser adquiridas por via de um sistema formal de ensino. Desta forma, tal como a primeira perspetiva, as competências são compreendidas como entidades ou atributos externos aos indivíduos. A terceira perspetiva apresentada pelo autor, as competências como traços ou características pessoais, entende as competências como características intrapessoais e define-as como capacidades que as pessoas podem ter. Relativamente à quarta, as competências "são consideradas como fenómenos intrapessoais e são definidas como resultados de desempenho ou modalidades de ação" (p.24).

Apresentadas as perspetivas destes dois autores, que têm como fim último tentar agrupar diferentes conceptualizações do conceito, parece-nos pertinente expor algumas dessas conceptualizações. Fleury \& Fleury (2001) defende que o conceito de competência tem que ver com um "saber agir responsável e reconhecido, que implica mobilizar, integrar, transferir conhecimentos, recursos e habilidades, que agreguem valor económico à organização e valor social ao indivíduo" (p.188). Zarifian (2003), estudioso de uma corrente francesa, entende as competências como uma forma de inteligência prática, que está alicerçada nos conhecimentos 
adquiridos, e os transforma, possibilitando aos indivíduos atuar em situações concretas, de complexidade distinta e crescente. Outro autor que propõe uma definição de competências é Ceitil (2007), entendendo-as como "modalidades estruturadas de ação, requeridas, exercidas e validadas num determinado contexto" (p.41). Para este autor as competências são comportamentos específicos que as pessoas apresentam, de uma forma regular, ao longo do seu desempenho profissional, e não comportamentos que se verificam de forma casual e esporádica, daí considerá-las como modalidades estruturadas de ação.

Apesar dos conceitos apresentados associarem as competências às pessoas, importa referir que existem outros autores que associam o conceito de competências às equipas de trabalho, ou mesmo às organizações. Prahalad \& Hamel (1990), por exemplo, consideram as competências como atributos organizacionais. Assim, apresentamos a proposta de Brandão \& Bahry (2005) no que diz respeito à classificação das competências, em dois grupos: as competências humanas ou profissionais, que estão relacionadas com os indivíduos ou com pequenas equipas de trabalho; e as competências organizacionais, que são inerentes às organizações, ou a uma das suas unidades produtivas. Chiavenato (2007) defende que as competências organizacionais podem ser explicadas pela Cascata de Competências Organizacionais (figura 1), a qual apresenta uma hierarquia entre as competências essenciais, funcionais, gerenciais e individuais também designadas de pessoais. Todas as competências estão interdependentes, articulando-se de forma a proporcionar resultados sistémicos e adequados a cada organização, alicerçando-se nas competências individuais.

Focando a atenção no objetivo deste trabalho, que passa pela identificação de competências de gestão (do enfermeiro com funções de chefia), parece-nos importante definir esta tipologia. De acordo com Ruas, Antonello, \& Boff (2005) as competências de gestão são aquelas que estão diretamente relacionadas com o trabalho de gestão nas organizações. Envolvem a capacidade de mobilizar, integrar e colocar os conhecimentos em ação, a fim de atingir ou superar desempenhos configurados à empresa, na respetiva área de atuação (idem). As competências de gestão devem ser constantemente atualizadas, pois mudam com o passar dos tempos (Chiavenato, 2007). Também exigem o desenvolvimento de habilidades operacionais, e a capacidade do gestor em lidar com as dinâmicas internas e externas das organizações, através do desenvolvimento de atitudes, valores e visões, adaptadas ao mundo envolvente (Dias \& Paiva, 2011). 
Figura 1 - Cascata de Competências Organizacionais (Adaptado de Chiavenato, 2007, p. 384)

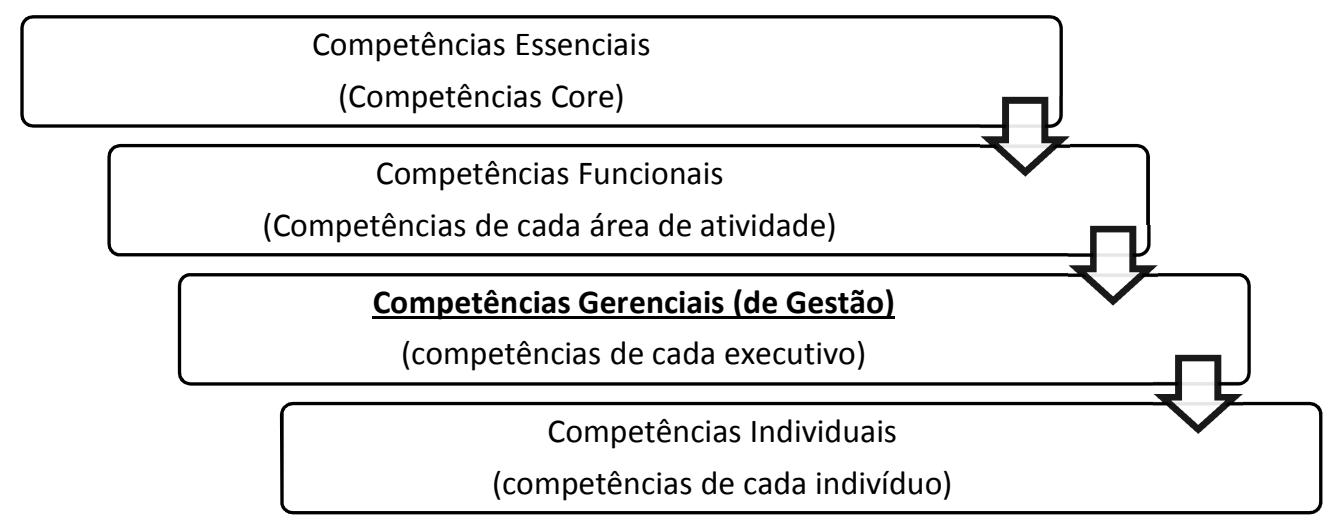

No que concerne ao estudo das competências aplicadas à disciplina de enfermagem não é, de modo nenhum, um assunto novo. São inúmeros os trabalhos publicados quer nacional, quer internacionalmente sobre competências dos profissionais de enfermagem. Por exemplo, as competências que um enfermeiro de cuidados gerais deve ter para o desempenho da sua função. Relativamente às competências para as funções de gestão dos enfermeiros, também existem diversos estudos publicados internacionalmente; contudo parece existir em Portugal uma lacuna de estudos sobre estas temáticas.

\section{Metodologia}

Para a realização deste trabalho procedemos a uma pesquisa bibliográfica em várias bases de dados (Ebsco; Google academic, B-on), em publicações de cariz científico, posteriores a 2005, com os descritores de pesquisa "competências", "gestão em enfermagem", "enfermeiro gestor", "competências gerenciais", "nursing management", "competencies", “competency". Dos diversos trabalhos encontrados, centramos a nossa atenção em trabalhos específicos da área da enfermagem, e selecionamos dezoito artigos: seis revisões de literatura, duas dissertações, dois estudos exploratórios com utilização de metodologia mista, cinco estudos exploratórios com uso 
IV Conferência Investigação e Intervenção em Recursos Humanos - Os Novos Contextos da Gestão de Recursos Humanos

de metodologia quantitativa e três publicações de organizações consideradas de referência na área da enfermagem ${ }^{1}$.

Posteriormente analisámos esses artigos, elencámos as competências mais referenciadas, e, através do procedimento de análise de conteúdo, construímos categorias, e definimo-las.

\section{Análise e Discussão dos dados}

Das dezoito publicações analisadas foi possível listar 189 competências. Dessas foram criadas dezoito categorias (Tabela 1) com a finalidade de as agrupar e, por conseguinte, reduzir o número das mesmas. $\mathrm{O}$ critério da construção das categorias baseou-se numa análise de conteúdo às 189 competências, de forma a encontrar pontos convergentes entre as mesmas. A Tabela 2 apresenta as categorias criadas, bem como as definições das mesmas.

Tabela 1 - Distribuição das 189 competências pelas categorias criadas

\begin{tabular}{|l|l|}
\hline$\underline{\text { Gestão de recursos humanos - 23 }}$ & Competências técnicas de gestão - 10 \\
$\underline{\text { Competências interpessoais - 21 }}$ & Resolução de problemas - 9 \\
$\underline{\text { Organização e planeamento - 17 }}$ & Iniciativa - 8 \\
$\underline{\text { Competências técnicas de enfermagem -15 }}$ & Pensamento crítico - $\mathbf{6}$ \\
$\underline{\text { Comunicação - 14 }}$ & Tecnologias de informação e Comunicação - $\mathbf{5}$ \\
$\underline{\text { Preocupação pela qualidade -133 }}$ & Ética - $\mathbf{5}$ \\
$\underline{\text { Conhecimento de políticas de saúde -11 }}$ & Adaptação à mudança - $\mathbf{4}$ \\
$\underline{\text { Resiliência e motivação - 11 }}$ & Trabalho em equipa - $\mathbf{3}$ \\
$\underline{\text { Liderança -11 }}$ & Autonomia - $\mathbf{3}$ \\
\hline
\end{tabular}

\footnotetext{
1 *ICN, American Organization of Nurse Executives e (AONE) American Association of Colleges of Nursing $(\mathrm{AACN})$
} 
Tabela 2 - Competências e sua definição

\begin{tabular}{|c|c|}
\hline$\frac{\text { Gestão de recursos }}{\underline{\text { humanos }^{2}}}$ & $\begin{array}{l}\text { Inclui conhecimentos nas práticas de recursos humanos, nomeadamente } \\
\text { recrutamento e seleção de pessoal, alocação de recursos de forma eficaz e eficiente, } \\
\text { mecanismos de gestão e avaliação do desempenho, bem como fornecimento de } \\
\text { oportunidades de formação contínua, educação, desenvolvimento e crescimento } \\
\text { profissional. }\end{array}$ \\
\hline $\begin{array}{l}\text { Competências } \\
\text { interpessoais }^{3}\end{array}$ & $\begin{array}{l}\text { É capaz de desenvolver uma cultura orientada para a equipa de forma a garantir não } \\
\text { só a satisfação dos seus colaboradores, como também, a sua segurança no que diz } \\
\text { respeito ao ambiente físico, instalações, equipamentos, e zelo pessoal em questões } \\
\text { de assédio sexual, violência no trabalho. }\end{array}$ \\
\hline$\frac{\text { Organização e }}{\text { planeamento }}$ & $\begin{array}{l}\text { Capacidade de estabelecer eficazmente um curso de ação para atingir pessoalmente } \\
\text { e/ou em grupo um objetivo. Inclui capacidades de efetuar avaliações sistemáticas } \\
\text { das necessidades futuras de pessoal de enfermagem em termos de números, dos seus } \\
\text { níveis de educação, habilidades e competências, bem como saber adaptar-se às } \\
\text { políticas relacionadas. Deve ainda ser capaz de planear e implementar mudanças } \\
\text { para a prestação de cuidados/serviços adequadas às necessidades previamente } \\
\text { identificadas. }\end{array}$ \\
\hline$\frac{\text { Competências técnicas de }}{\text { enfermagem }}$ & $\begin{array}{l}\text { Capacidade de prestar cuidados de enfermagem, servindo como referência aos seus } \\
\text { pares, por meio de experiência profissional reconhecida. }\end{array}$ \\
\hline Comunicacão & $\begin{array}{l}\text { Expressa ideias ou factos de forma clara e persuasiva, usando eficazmente } \\
\text { linguagem verbal e não-verbal. Manifesta segurança na informação prestada aos } \\
\text { outros, de modo a que estes sejam convencidos e impressionados, por forma a } \\
\text { obterem a sua aceitação e compreensão ou concordância. }\end{array}$ \\
\hline$\frac{\text { Preocupacão pela }}{\text { qualidade }}$ & $\begin{array}{l}\text { Identifica e implementa medidas para melhorar a qualidade dos cuidados prestados, } \\
\text { bem como do aumento da produtividade. Preocupa-se em que os clientes internos e } \\
\text { externos manifestem satisfação com os serviços prestados quer por ele próprio, quer } \\
\text { pela sua equipa. }\end{array}$ \\
\hline Conhecimento de políticas & $\begin{array}{l}\text { Demonstra conhecimentos sobre promoção de saúde e prevenção de doença; faz } \\
\text { corretamente uma gestão da saúde/doença no desempenho das suas funções. } \\
\text { Demonstra conhecimentos sobre legislação na área da saúde em Portugal }\end{array}$ \\
\hline$\underline{\text { Resiliência e motivação }}$ & $\begin{array}{l}\text { Evidencia, através de comportamentos, uma rápida recuperação, quando } \\
\text { confrontado com situações de rutura, stresse e/ou emocionalmente } \\
\text { descompensatórias. Apresenta capacidade para estimular os outros a seguir um } \\
\text { determinado rumo ou direção, mesmo nas circunstâncias mais adversas. }\end{array}$ \\
\hline$\underline{\text { Lideranca }}^{4}$ & $\begin{array}{l}\text { Motiva, possibilita e inspira os outros a serem bem sucedidos utilizando os estilos } \\
\text { apropriados. Tem uma visão clara do que é pedido, e, atua enquanto um modelo } \\
\text { positivo, utilizando apropriadamente estilos interpessoais e métodos de condução de } \\
\text { indivíduos ou grupos, para a realização de tarefas. Inclui os conhecimentos, } \\
\text { habilidades e capacidades que permitem ao líder fortalecer os que o rodeiam, e } \\
\text { aproveitar os seus pontos fortes para o esforço coletivo. }\end{array}$ \\
\hline
\end{tabular}

\footnotetext{
${ }^{2}$ Baseado na publicação do ICN - Reid \& Weller (2010)

${ }^{3}$ Baseado na publicação do ICN - Reid \& Weller (2010)

${ }^{4}$ Adaptado da publicação do ICN - Reid \& Weller (2010)
} 
IV Conferência Investigação e Intervenção em Recursos Humanos - Os Novos Contextos da Gestão de Recursos Humanos

\begin{tabular}{|c|c|}
\hline$\frac{\text { Competências técnicas de }}{\text { gestão }}$ & $\begin{array}{l}\text { É capaz de construir, analisar e/ou interpretar indicadores de performance } \\
\text { organizacional. }\end{array}$ \\
\hline$\underline{\text { Resolucão de problemas }}$ & $\begin{array}{l}\text { É capaz de analisar situações problemáticas de trabalho, verificando as relações de } \\
\text { causa/efeito e estabelecendo prioridades de atuação de forma eficaz e eficiente. }\end{array}$ \\
\hline$\underline{\text { Iniciativa }}$ & $\begin{array}{l}\text { Influencia ativamente as ocasiões em vez de as aceitar passivamente, originando } \\
\text { ação. Identifica oportunidades e atua sobre elas. Empreende projetos de mudança de } \\
\text { modo a adaptar-se às exigências que o rodeiam. }\end{array}$ \\
\hline$\underline{\text { Pensamento crítico }}$ & $\begin{array}{l}\text { Apresenta capacidades de análise e avaliação da consistência de raciocínios; é capaz } \\
\text { de decidir racionalmente sobre quais as ideias ou informações que devem ser } \\
\text { admitidas. }\end{array}$ \\
\hline Tecnologias de informacão & $\begin{array}{l}\text { É capaz de utilizar as ferramentas informáticas disponíveis nas suas áreas de } \\
\text { influência e atuação, facilitando as diversas relações que estabelece, nos mais } \\
\text { diversos campos de atuação }\end{array}$ \\
\hline$\underline{\text { Ética }^{5}}$ & $\begin{array}{l}\text { Inclui os comportamentos e ações que visam garantir uma prática de enfermagem } \\
\text { dentro de uma estrutura ética e profissional. Enfermeiros demonstrando } \\
\text { competências neste domínio irão apresentar padrões de comportamento cortês e } \\
\text { profissional, respeitando as normas jurídicas e éticas, os valores comuns de } \\
\text { indivíduos e grupos, esforçando-se para uma melhoria contínua da prestação de } \\
\text { serviços e do pessoal de enfermagem. }\end{array}$ \\
\hline Adaptação à mudança & $\begin{array}{l}\text { É capaz de compreender as constantes mutações que ocorrem no mundo que o } \\
\text { rodeia, e procurar preparar-se para essas transformações. Em vez de criticar a } \\
\text { mudança, procura entendê-la, e integrar-se, da melhor forma possível, ao novo } \\
\text { ambiente. }\end{array}$ \\
\hline$\underline{\text { Trabalho em equipa }}$ & $\begin{array}{l}\text { Apresenta disponibilidade para participar enquanto membro de uma equipa da qual } \\
\text { ele/ela não é necessariamente líder. Revela ser um colaborador eficaz mesmo } \\
\text { quando a equipa está a trabalhar em algo que não possui um interesse pessoal direto, } \\
\text { em prol dessa mesma equipa. }\end{array}$ \\
\hline$\underline{\text { Autonomia }}$ & $\begin{array}{l}\text { Revela, de forma independente, prontidão na tomada de decisões, na enunciação de } \\
\text { opiniões, na tomada de ação ou no comprometimento com alguma situação. }\end{array}$ \\
\hline
\end{tabular}

De acordo com a nossa pesquisa, a $\mathrm{OE}$ não tem publicado nenhum diploma onde estejam definidas as competências que o enfermeiro com funções de gestão deve encerrar, nem mesmo tem previsto publicamente nenhum trabalho neste sentido. Contudo, o órgão que serviu de referência para o documento já referido das "Competências dos Enfermeiros de Cuidados Gerais" publicado em 2003 pela OE, o ICN, publicou em 2010, um documento intitulado "Nursing Human Resources Planning and Management Competencies", onde apresenta as competências core que irão permitir aos enfermeiros gerir eficaz e eficientemente, os recursos de enfermagem dos serviços de saúde (Reid, et al., 2010, pág.9). Como os trabalhos do ICN foram

\footnotetext{
${ }^{5}$ Baseado na publicação do ICN - Reid \& Weller (2010)
} 
IV Conferência Investigação e Intervenção em Recursos Humanos - Os Novos Contextos da Gestão de Recursos Humanos

anteriormente valorizados pela OE na definição das competências do enfermeiro de cuidados gerais, optamos por comparar as categorias mais frequentes, a que apelidamos de "top" com as que o ICN propõe (Tabela 3).

Tabela 3 - Comparação das competências mais encontradas após categorização (Top Categorias), com as identificadas pelo ICN (2010)

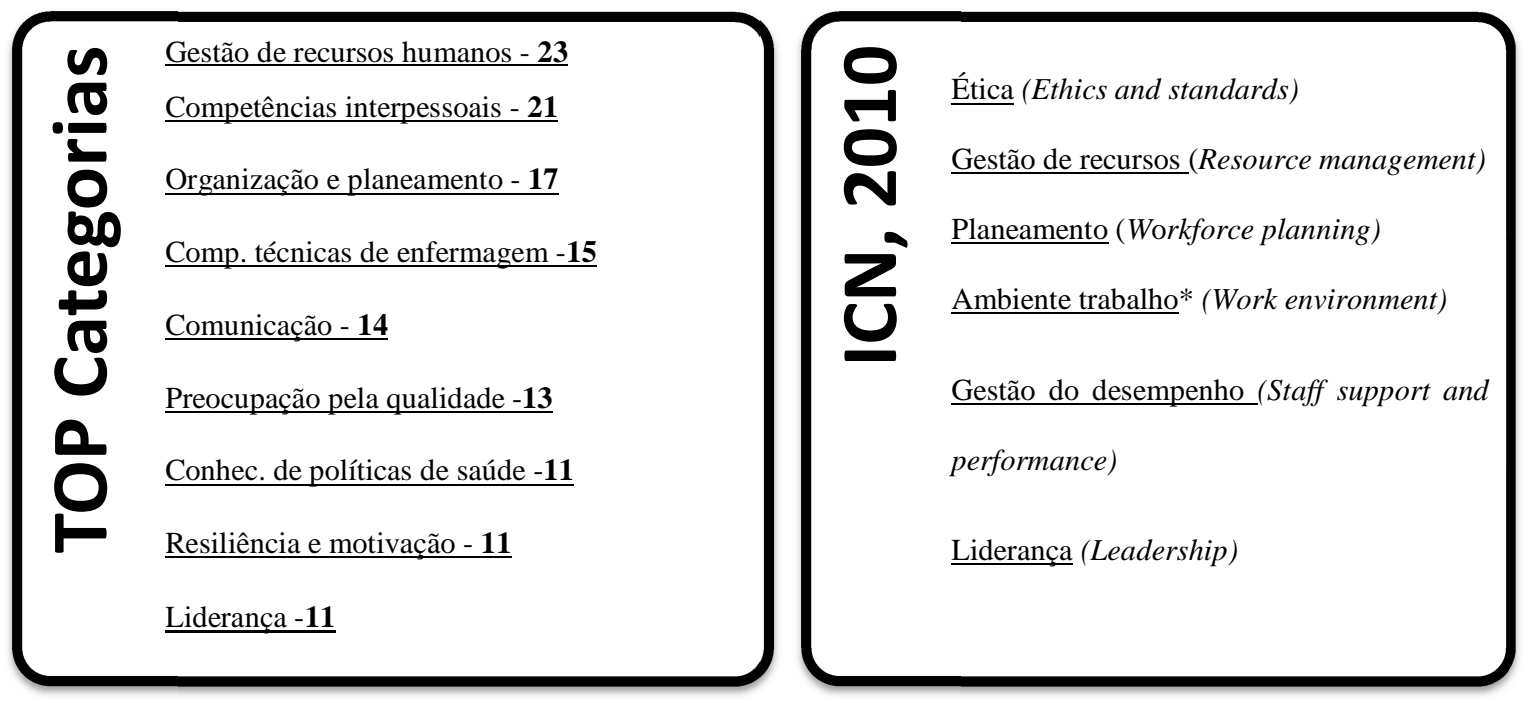

Apesar das terminologias utilizadas, por vezes, não coincidirem, consideramos que existe uma certa comparabilidade entre as categorias que mais encontramos (que designamos de 'top'), com as categorias propostas pelo ICN para as funções de gestão de um enfermeiro. Esta comparação baseia-se na análise do descritivo das competências previsto pelo ICN, e na própria definição das categorias por nós criadas. Aliás, em muitos casos, as mesmas foram beber aos trabalhos do ICN. A título de exemplo, demonstramos que a nossa competência Gestão de Recursos Humanos coincide quer com a Gestão de Recursos, quer com a Gestão do Desempenho, previstos pelo ICN (Tabela 4). Já a categoria Comunicação está incluída no Ambiente de Trabalho. Relativamente à competência Ética prevista pelo ICN, nós também a consideramos, contudo, como podemos constatar, não faz parte do top que identificámos. 
Tabela 4 - Comparação das competências identificadas (após categorização), com as definidas pelo ICN (2010)

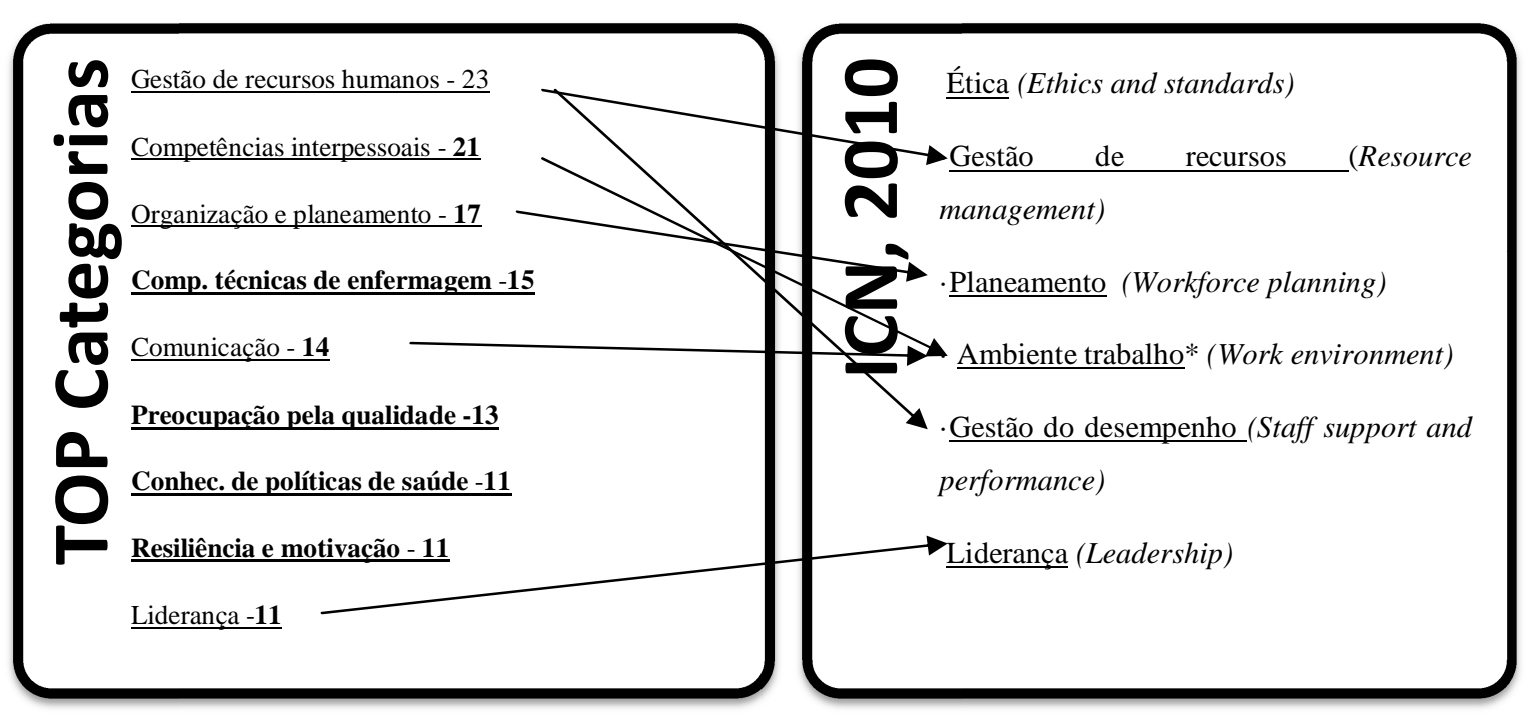

Uma das análises que também consideramos importante referir, relativamente à comparação do top por nós identificado e as competências propostas pelo ICN, é que estes não consideram as competências técnicas específicas, mas apenas competências transversais. Este facto pode ser explicado pela existência de outros trabalhos já publicados pelo ICN (como o Framework of Competencies for the Generalist Nurses), que preveem que os enfermeiros passem por diferentes etapas ao longo do seu percurso profissional, e sejam detentores dessas competências técnicas, quando chegam a este patamar da sua carreira. Mas, na verdade, no documento Nursing Human Resources Planning and Management Competencies as competências técnicas não são tidas em consideração.

\section{Conclusão}

Este trabalho teve como principal objetivo identificar, através de uma análise da literatura, as competências mais importantes e mais valorizadas para as funções de gestão executadas por enfermeiros. Consideramos que esta identificação poderá ser muito profícua a diversos níveis. 
28 e 29 de janeiro de 2013

De acordo com uma publicação do ICN (2003), a definição de um quadro de competências em enfermagem, possibilita uma demonstração clara dos papéis e responsabilidades destes profissionais, quer individual, quer coletivamente. Também pode fornecer uma base para a conceção de currículos de formação de enfermeiros e enfermeiros gestores mais adaptados, tanto na teoria como na prática, garantindo que os cuidados de saúde e, especificamente, os de enfermagem, atendam às necessidades dos tempos que correm. Ainda podem auxiliar na especificação das expectativas profissionais associadas aos papéis/ funções dos enfermeiros (ICN, 2003, cit. por Reid \& Weller, 2010) pelas entidades que os contratam.

Também possibilitará melhorar o desempenho dos indivíduos que desenvolvem atualmente esta função, pois podem gerir e monitorizar o seu desempenho, através da identificação das competências que necessitem ser desenvolvidas.

Outro aspeto a ter em consideração é que a avaliação de competências (tendo por base os diferentes níveis de exigência) poderá promover a identificação de potenciais talentos, que, por sua vez, poderá possibilitar melhores desempenhos da Administração Pública Portuguesa.

Consideramos que a falta de estudos nesta área em específico, em Portugal, será uma das principais limitações deste estudo. Posto isto, arguimos que este trabalho será um estudo inicial para a identificação das competências mais importantes dos enfermeiros com funções de gestão, no nosso país. Apesar de na recente carreira dos Enfermeiros (Decreto-lei 247/2009 e Decreto-lei 248/2009, de 22 de Setembro) estar previsto que a categoria de Enfermeiro Principal possa desempenhar funções de gestão, esta ainda não entrou em vigor. Certamente que a definição das competências poderá ser um elemento facilitador para a concretização da legislação.

\section{Bibliografia}

AACN. (2007). White Paper on the Education and Role of the Clinical Nurse Leader. American Association of Colleges of Nursing.

Almeida, P., \& Rebelo, G. (2011). A era da competência: Um novo paradigma para a gestão de recursos humanos e o direito do trabalho. Lisboa: Editora RH.

Bauer Feldman, L., Ruthes, R. M., \& Olm Cunha, I. C. (2008). Criatividade e inovação: competências na gestão de enfermagem. Revista Brasileira de Enfermagem , 61, 239-242.

Boterf, G. L. (Junho de 2006). Avaliar a Competência de um Profissional, Três dimensões a explorar. Reflexão RH, pp. 60-63. 
Boyatzis, R. (1982). Competence and job performance. In R. Boyatzis, The competente manager, A model for effective performance (pp. 10-39). New York: John Wiley \& Sons.

Boyatzis, R. (2008). Competencies in the 21st century. Journal of Management Developement, 5-12.

Brandão, P. H., \& Bahry, C. P. (Abr/Jun de 2005). Gestão por Competências: métodos e técnicas para mapeamento de competências. Revista do Serviço Público , pp. 179-194.

Cadmus, E. (2006). Succession planning multilevel organizational strategies for the new workforce. The Journal of Nursing Administration, 36, 298-303.

Camara, P. B., Guerra, P. B., \& Rodrigues, J. V. (2010). Novo Humanator, Recursos Humanos e Sucesso Empresarial. Alfagide: Publicações Dom Quixote.

Carapeto, C., \& Fonseca, F. (2006). Administração Pública - Modernização, Qualidade e Inovação (2ª Edição ed.). Lisboa: Edições Sílabo.

Cascão, F. (2004). Entre a Gestão de Competências e a Gestão do Conhecimento, Um Estufo Exploratório de Inovações na Gestão das Pessoas. Lisboa: Editora RH.

Ceitil, M. (. (2007). Gestão e Desenvolvimento de Competências (1ª Edição ed.). Lisboa: Edições Sílabo Lda.

Ceitil, M. (2010). Gestão e Desenvolvimento de Competências. Lisboa: Sílabo.

Chase, L. K. (2010). Nurse manager competencies. University of Iowa, Dissertation.

DeOnna, J. (2006). Developing and Validating an Instrument to Measure the Perceived Job Competencies Linked to Performance and Staff Retention of First-Line Nurse Managers Employed in a Hospital Setting. A Thesis in Workforce Education and Development. The Pennsylvania State University - Graduate School College of Education: Submitted in Partial Fulfillment of the Requirements for the Degree of Doctor of Philosophy.

Dias, H. C., \& Paiva, K. C. (2011). Competências do enfermeiro: estudo em um hospital privado. Revista Brasileira de Enfermagem .

Fleury, M., \& Fleury, A. (2001). Construindo o Conceito de Competência. Revista de Administração Contemporânea, 183-196.

Huston, C. (2008). Preparing nurse leaders for 2020. Journal of Nursing Management , 16, 905-911.

Jennings, B. M., Scalzi, C. C., Rodgers, J. D., \& Keane, A. (2007). Differentiating nursing leadership and management competencies. Nursing Outlook, 55, 169-175.

Kagan, I., Kigli-Shemesh, R., \& Tabak, N. (2006). Let me tell you what I really think about you' - evaluating nursing managers using anonymous staff feedback. Journal of Nursing Management , 14, 356-365.

Le Boterf, G. (2011). Ingénierie et évaluation des compétences ( $6^{\mathrm{a}}$ ed.). Paris: Editions d'Organisation.

Lei n. ${ }^{\circ} 111 / 2009$ de 16 de Setembro. Anexo do Estatuto da Ordem dos Enfermeiros, art. ${ }^{\text {3, n. }}{ }^{\circ} 1$.

Lewis, R., Yarker, J., Donaldson-Feilder, E., Flaxman, P., \& Munir, F. (2010). Using a competency-based approach to identify the management behaviours required to manage workplace stress in nursing: a critical incident study. International Journal of Nursing Studies , 307-313.

Lin, L., Wu, J., Huang, I., Tseng, K., \& Lawler, J. (2007). Management Development: A Study of Nurse Managerial Activities and Skills. Journal of Healthcare Management , 52, 157-169.

Lorber, M., \& Savič, B. S. (2011). Perceptions of managerial competencies, style, and characteristics among professionals in nursing. Croat Medicine Journal , 52, 198-204.

McCarthy, G., \& Fitzpatrick, J. J. (2009). Development of a Competency Framework for Nurse Managers in Ireland. The Journal of Continuing Education in Nursing , 40, 346-350.

McClelland, D. (Janeiro de 1973). Testing for Competence Rather than for "Intelligence". American Psychologist , pp. 1-14.

OCDE. (07 de outubro de 2002). Definition and Selection of Competences (DESECO): Theoretical and Conceptual Foundations. Strategy Paper. Obtido em 08 de outubro de 2012, de http://mt.educarchile.cl/MT/jjbrunner/archives/libros/Competencias/Estrategia.pdf

Organização Internacional do Trabalho. (2002). Glossário de Termos Técnicos - Certificação e Avaliação de Competências. Brasília: OIT. 
IV Conferência Investigação e Intervenção em Recursos Humanos - Os Novos Contextos da Gestão de Recursos Humanos

Escola Superior de Ciências Empresariais do Instituto Politécnico de Setúbal 28 e 29 de janeiro de 2013

Peres, A. M., \& Ciampone, M. H. (Jul-Set de 2006). GERÊNCIA E COMPETÊNCIAS GERAIS DO ENFERMEIRO. Texto Contexto Enferm , 492-499.

Pillay, R. (2010). The skills gap in nursing management in South Africa: a sectoral analysis: a research paper. Journal of Nursing Management, 18, 134-144.

Pillay, R. (2010). Towards a competency-based framework for nursing management education. International Journal of Nursing Practice , 16, 545-554.

Prahalad, C. K., \& Hamel, G. (May/June de 1990). The core competence of the corporation. Harvard Business Review , 68, pp. 79-91.

Reid, U. V., \& Weller, B. (2010). Nursing Human Resources Planning and Management Competencies. Switzerland: International Council of Nurses (ICN).

Ruas, R., Antonello, C. S., \& Boff, L. H. (2005). Os Novos Horizontes da Gestão - Aprendizagem Organizacional e Competências. São Paulo: Artmed Editora.

Ruthes, R. M., \& Cunha, I. C. (Dez de 2007). Contribuições para o conhecimento em gerenciamento de enfermagem sobre gestão de competências. Ruthes, Rosa Maria e Cunha, Isabel C.K.O. 2007. Contribuições para o conhecimento Rev Gaúcha de Enfermagem , pp. 570-575.

Ruthes, R. M., \& Cunha, I. C. (jan-fev de 2007). Entendendo as competências para a aplicação na enfermagem. Revista Brasileira de Enfermagem , vol.61, pp. 109-112.

Silva, P. (2008). Competências Transversais dos Licenciados e sua Integração no Mercado de Trabalho. Guimarães: Universidade do Minho.

Sutto, N. B., Knoell, M. D., Zucker, K., Finstuen, K., \& Mangelsdorff, D. (2008). Executive Competencies of Nurses in the Veterans Health Administration. MILITARY MEDICINE, 173, 47-53.

Zarifian, P. (2003). O modelo de competência: trajaetória histórica, desafios atuais e propostas (2a ed.). São Paulo: Senac. 